\title{
LETTER
}

\section{A plea for balanced reporting}

\author{
Mervyn Singer* \\ See related research by Mayer et al., http://ccforum.com/content/14/1/R18
}

I read with interest the study by Mayer and colleagues on intraoperative hemodynamic optimization using Flotrac/ Vigileo [1]; however, the imbalance in their discussion needs redressing. Citing a meta-analysis of esophageal Doppler cardiac output $(\mathrm{CO})$ validation studies that I coauthored [2], they claimed this showed 'limited accuracy' and that 'absolute $\mathrm{CO}$ measurements were found to be imprecise.' Surprisingly, they made no mention of a similar meta-analysis they published last year on the FloTrac/Vigileo system [3] where the precision and bias of the second generation device were no better!

Clearly, they wish to promote the device they use and believe in, but it does no service to the medical and scientific community to misrepresent one technology over another. For example, they make no mention of the limitations of the $12 \%$ pulse pressure variation value used to predict fluid responsiveness; with tidal volumes $<8 \mathrm{ml} /$ $\mathrm{kg}$, accuracy is only $51 \%$ [4] yet they did not report tidal volumes delivered. Nor do they mention the inferior results reported last year in an independent comparison of the two devices undertaken for the French Agence d'Evaluation des Produits de Sante [5].
They did acknowledge an overall reduction of hospital stay and complication rates in five Doppler-directed perioperative optimization studies (actually, nine such studies are published to date). Is this not at odds with the claimed 'imprecision'? They may be interested to learn of a recent UK National Health Service Technology Adoption Centre implementation project involving 1,247 surgical patients in 3 hospitals where these research findings could be reproduced in routine clinical practice, with a 3-day reduction in hospital stay and fewer postoperative complications [6]. I openly declare my affection for the Doppler technology. It too has its imperfections but the onus is on other monitoring devices to achieve consistently similar - if not better - outcomes in prospective randomized controlled trials. I conclude with a general plea to advocates of any device or management strategy to present a balanced view of advantages and limitations, and to move away from partisan reporting. The general knowledge base on $\mathrm{CO}$ monitoring devices is woefully inadequate so it is incumbent upon the aficionado to educate properly.

\section{Authors' response}

Jochen Mayer, Joachim Boldt, Andinet Mengistu, Kerstin D Röhm and Stefan Suttner

We thank Dr Singer for his interest in our recently published article [1]. We would like to address some of the issues raised by Dr Singer. The purpose of our article was to demonstrate that intraoperative hemodynamic optimization with the easy-to-use FloTrac/Vigileo device results in an improved outcome. We did not disavow that intraoperative optimization also works with other techniques. The scope of our study had to be kept within the limits of a research article and not all available literature could therefore be mentioned or discussed. Nevertheless, we tried to give a short overview of other techniques and cited the peer-reviewed meta-analysis of the esophagus Doppler method by Dark and Singer [2].

*Correspondence: m.singer@ucl.ac.uk

University College London, Cruciform Building, Gower Street, London WC1E 6BT, UK
This publication states 'significant differences in the median percentage of clinical agreement' between esophagus Doppler and bolus pulmonary artery thermodilution.

The ability of the FloTrac to predict fluid responsiveness was shown by Hofer and colleagues [7]. Tidal volumes of controlled mechanical ventilation were $8 \mathrm{ml} / \mathrm{kg}$ bodyweight or higher in all patients during the measurement periods in our study.

\section{Abbreviations \\ $\mathrm{CO}=$ cardiac output.}

\section{Competing interests}

MS was heavily involved in the development of the CardioQ esophageal Doppler monitor and performs consultancy work for Deltex Medical. University College London is the beneficiary of unrestricted donations for research and the University holds shares in Deltex Medical bequeathed by the Pauline Thomas Charitable Trust. JM and JB received speaking fees from Edwards Lifesciences, Irvine, CA, USA.

Published: 20 April 2010 


\section{References}

1. Mayer J, Boldt J, Mengistu AM, Röhm KD, Suttner S: Goal-directed intraoperative therapy based on autocalibrated arterial pressure waveform analysis reduces hospital stay in high-risk surgical patients: a randomized, controlled trial. Crit Care 2010, 14:R18.

2. Dark PM, Singer M: The validity of trans-esophageal Doppler ultrasonography as a measure of cardiac output in critically ill adults. Intensive Care Med 2004, 30:2060-2066.

3. Mayer J, Boldt J, Poland R, Peterson A, Manecke GR Jr: Continuous arterial pressure waveform-based cardiac output using the FloTrac/Vigileo: a review and meta-analysis. J Cardiothor Vasc Anesth 2009, 23:401-406.

4. De Backer D, Heenen S, Piagnerelli M, Koch M, Vincent JL: Pulse pressure variations to predict fluid responsiveness: influence of tidal volume. Intensive Care Med 2005, 31:517-523.

5. Chatti R, De Rudniki S, Marqué S, Dumenil AS, Descorps-Declère A, Cariou A, Duranteau J, Aout M, Vicaut E, Cholley BP: Comparison of two versions of the Vigileo-FloTrac system (1.03 and 1.07) for stroke volume estimation: a multicentre, blinded comparison with oesophageal Doppler measurements. Br J Anaesth 2009, 102:463-469.

6. Doppler Guided Intraoperative Fluid Management [http://www. technologyadoptionhub.nhs.uk/doppler-guided-intraoperative-fluidmanagement/executive-summary.html]

7. Hofer CK, Senn A, Weibel L, Zollinger A: Assessment of stroke volume variation for prediction of fluid responsiveness using the modified FloTrac $^{\mathrm{TM}}$ and PiCCOplus ${ }^{\mathrm{TM}}$ system. Crit Care 2008, 12:R82.

doi:10.1186/cc8942

Cite this article as: Singer M: A plea for balanced reporting. Critical Care 2010, 14:414. 